\title{
Implementasi Augmented Reality untuk Pengenalan Lokasi Boombara Waterpark
}

\author{
Daniel Sitohang $^{\mathbf{1}^{*}}$, Nurjayadi ${ }^{2}$ \\ ${ }^{1}$ Teknik Informatika, STMIK Amik Riau, , Pekanbaru-Riau \\ ${ }^{2}$ Manajemen Informatika, STMIK Amik Riau, Pekanbaru- Riau \\ *E-mail: sitohang238@gmail.com
}

\begin{abstract}
The development of information technology and marketing has been grow rapidly and it best to make an interactive advertise and a creative idea on promotion. Boombara Waterpark is one of a place people should visit when in Pekanbaru. Boombara Waterpark has a large parking area and it can make the visitor feel more safe. This place has another facilities like musholla, food court, and the wide stage with high quality sound system. But the fact is people still don't exactly know the location of Boombara Waterpark. Augmented Reality is a technology that combines two-dimensional and or three-dimensional virtual objects into things that seems real. In this research, the author promote Boombara Waterpark with augmented Reality, people know every detail about the location and the facilities in Boombara Waterpark.
\end{abstract}

Keywords: polygonal modelling, augmented reality

\begin{abstract}
Abstrak
Pesatnya perkembangan teknologi informasi maupun promosi dalam dunia periklanan, maka sangat diperlukannya berbagai ide interaktif dan creative yang untuk menghasilkan promosi yang menarik. Wisata Boombara Waterpark merupakan salah satu destinasi wisata air yang patut untuk dikunjungi bila anda sedang berada di Pekanbaru. Boombara Waterpark ini memiliki lahan parkir yang luas dan membuat pengunjung merasa lebih aman, Boombara Waterpark juga dilengkapi dengan fasilitas umum lain seperti musholla, food court dan panggung terbuka lengkap dengan sounds sistem berkualitas tinggi. Tapi masih banyak masyarakat yang belum mengetahui lokasi letak wisata Boombara Waterpark. AugmentedReality adalah teknologi yang menggabungkan benda maya atau tidak nyata dua dimensi dan ataupun tiga dimensi ke dalam sebuah hal yang seolah nyata tiga dimensi lalu memproyeksikan benda-benda maya tersebut dalam waktu nyata sehingga terjadi interaksi fisik antara maya dan nyata. Dengan adanya AugmentedReality dalam pengenalan Boombara Waterpark, pengunjung semakin tahu setiap detail dan fasilitas yang disediakan di dalam Boombara Waterpark karena semakin menarik pengunjung.
\end{abstract}

Kata kunci: poligonal modelling, augmented reality

\section{PENDAHULUAN}

Kebutuhan teknologi berkembang
seiring dengan perkembangan zaman. Bermacam teknologi telah diciptakan untuk berbagai keperluan dan pada berbagai bidang ilmu, salah satunya dibidang informasi yang digunakan sebagai media penjualan dan promosi, dimana sekarang promosi yang dilakukan oleh sebuah perusahaan tertentu tidak lagi dilakukan secara manual melainkan dipromosikan dengan menggunakan salah satu bentuk teknologi informasi yang berkembang yaitu Augmented Reality. Menurut Tambayong[1]Augmented Realityyaitu teknologi yang menggabungkan benda maya dua dimensi maupun tiga dimensi ke dalam sebuah lingkungan nyata tiga dimensi lalu memproyeksikan benda-benda maya tersebut dalam waktu nyata (real time). Media ini dapat berupa kertas, sebuah marker atau penanda melalui perangkat perangkat input tertentu. Teknologi ini tidak sepenuhnya menggantikan sebuah realitas, tapi menambahkan (augment) sebuah atau beberapa benda - benda maya dalam bentuk 2 atau 3 dimensi ke dalam lingkungan nyata 3 dimensi dan ditampilkan secara real time.

Menurut Murtini [2][3] Waterpark adalah suatu tempat berisi segala aktivitas manusia dalam memanfaatkan waktu senggangnya secara konstruktif dan menyenangkan pada area publik atau privat yang dirancang untuk kebutuhan estetika, rekreasi, mental dan emosional untuk 
mendapatkan kepuasan dan kesenangan dengan memanfaatkan air sebagai faktor utama baik secara langsung maupun tidak langsung. Boombara Waterpark, sebuah wahana wisata air yang berada di kawasan Komplek Perum Griya Pasir Putih dan beralamat di Jalan J1. Raya Pasir Putih KM 5 Kec. Siak Hulu, Kab. Kampar. dengan masih menggunakan media sosial seperti Facebook dan Instagram untuk media promosi yang hanya mengenalkan lokasi dan wahana Boombara dalam bentuk foto atau 2D dan juga lewat voucher promosi yang tidak menjelaskan bagaimana lokasi Boombara dan apa saja wahananya, perlu sebuah teknologi seperti Augmented Reality untuk mengenalkan lokasi dan wahana Boombara Waterpark agar pengunjung semakin mengenali bagaimana lokasi dan wahana Boombara Waterpark.

Menurut Chandra [4]Polygonal Modelingadalah sebuah teknik pemodelan dalam bentuk 3D. Polygonal modeling merupakan tipe pemodelan yang terdiri atas sekumpulan polygonal dengan minimal tiga titik atau vertex dari setiap polygon, sekumpulan dari polygon tersebut akan menghasilkan sebuah model objek 3D. Teknil polygonal modeling merupakan penerapan teknik objek-objek geometri dasar yang kemudian dikembangkan menjadi objek model yang lebih kompleks. Umumnya memakai bentuk objek geometri box (kotak) yang kemudian dihaluskan lagi permukaannya (smooth). Model polygonal sangat fleksibel dan dapat ditampilkan oleh komputer dengan sangat cepat. Sehingga pada penelitian kali ini peneliti akan membuat pemodelan bangunan dengan menggunakan metode Polygonal Modeling untuk membentuk lokasi dan wahana Boombara Water Park.

Dari permsalahan diatas digunakanlah teknologi Augmented Reality sebagai salah satu solusi untuk menyelesaikan permasalahan dan diharapkan bisa menambah media promosi untuk pengenalan lokasi Boombara Water Park dan pengunjung semakin antusias dan tertarik mengunjungi Boombara Water Park.

\section{METODOLOGI}

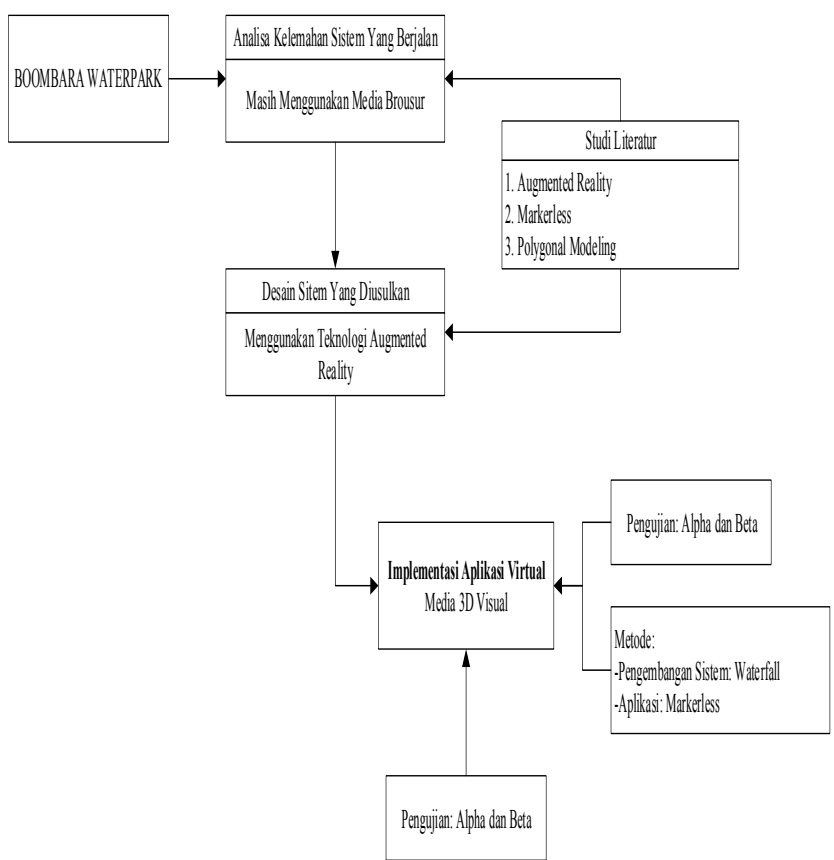

Gambar 1. Tahapan penelitian dan perancangan

Berdasarkan gambar 1, teknik pengembangan sistem yang digunakan adalah model waterfall. Model ini adalah model klasik yang melakukan pendekatan secara sistematis, berurutan dalam membangun software. Tahapan-tahapannya adalah analisis dan definisi persyaratan, Perancangan sistem dan perangkat lunak, Implementasi dan pengujian unit, Integrasi dan pengujian sistem, dan operasi dan pemeliharaan.

Langkah pertama yang dilakukan adalah menganalisa kelemahan media pembelajaran yang digunakan saat ini, kuisioner mahasiswa dibutuhkan dalam tahap ini. Kemudian hasil analisa yang dilakukan dituangkan kedalam sebuah perancangan atau desain. Pada tahap tersebut studi literature diperlukan, untuk memahami teori-teori yang berkaitan dengan penelitian. Hasil desain kemudian diimplementasikan menjadi aplikasi virtual yang memanfaatkan teknologi AR, berupa media pembelajaran 3D Visual.

Pengujian kelayakan sistem menggunakan alpha testing dan beta testing. Pengujian dilakukan terhadap aplikasi untuk memastikan bahwa aplikasi dapat berjalan dengan benar sesuai dengan kebutuhan dan tujuan yang diharapkan. Pengujian Beta dilakukan secara langsung terhadap pengguna dengan menggunakan kuesionerparagraf. 


\section{HASIL DAN PEMBAHASAN}

Untuk melaksanakan penelitian ini tentunya membutuhkan alat pendukung berupa perngkat keras dan perangkat lunak, alat-alat yang digunakan dijelaskan sebagai berikut :

\section{Laptop}

a.Processor Intel Core i5-5200M 2.20GHz

\section{b.DDR3 RAM 4GB}

c.Graphic Card Intel HD Graphics 5500

d.Render NVIDIA GeForce 820Mdekatnya.

2.Ponsel Android

a.Processor Octa-core $2.0 \mathrm{GHz}$ Cortex-A53

b.RAM 2GB

c.GPU PowerVR G6200

d.Display 5.5 inch, $1080 \times 1920$ pixels

e.Kamera $13 \mathrm{MP}$

f.Chipset Mediatek MT6795 Helio X10.

Berikut adalah tabel spesifikasi perangkat lunak yang digunakan selama pengembangan sistem.

1. Laptop

- Windows 10 Pro 64-bit sebagai sistem operasi.

- Unity Game Engine 5.6.2f1 sebagai aplikasi pengembangan android.

- Blender 2.78b sebagai aplikasi pemodelan objek.

- Visual Studio 2017. Sebagai scripting editor.

- Vuforia 6.2.10. Sebagai SDK Augmented Reality.

- Android SDK. Sebagai Compiler untuk membuat Android package (.apk)

- Adobe Photoshop CS6. Sebagai editor gambar.

2. Ponsel Android

- Android 5.0.2 (Lollipop) sebagai sistem operasi.

\section{Implementasi \\ Implementasi Pemodelan Objek dengan Polygonal Modelling}

Pada pembuatan aplikasi ini penulis membuat dua belas buah objek bangunan dan wahana permainan air. Namun karena proses pembuatan dari masing-masing objek membutuhkan waktu yang lama maka penulis akan menampilkan hasil salah satu objek 3D.

Untuk membuat objek kids pool yang harus dilakukan adalah pertama membuat objek silinder untuk menggambarkan wahana permainan air, dengan cara memilih menu $A d d$ lalu pilih Mesh dan pilih Cylinder.

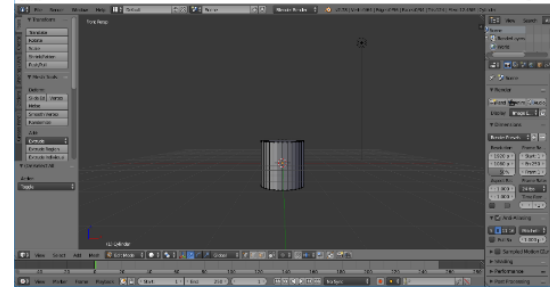

Gambar 3 Membuat Cylinder pertama

Selanjutnya dengan menggunkan polygonal modelling yang terdiri dari vertices (vertex/titik) yang jika disambungkan akan membentuk sebuah edge (garis), sehingga jika disambungkan dengan edge lain dapat membentuk sebuah face (bidang).

Selanjutnya dengan polygonal modelling membuat cylinder menjadi objek wahana kidspool.

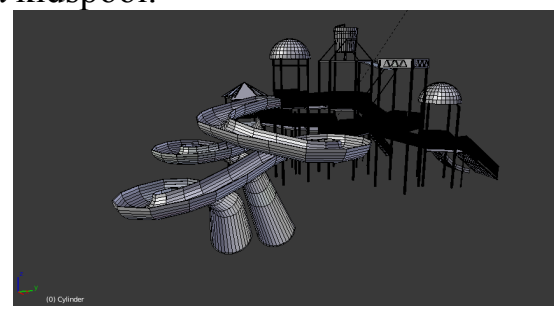

Gambar 2 Hasil Wahana Kidspool dengan polygonal modelling

\section{Implementasi Rancangan Marker}

Pada tahap pembuatan marker penulis membuat 1 buah marker. Dalam tahap pembuatan marker penulis menggunakan aplikasi Adobe Photoshop CS6.

Buka aplikasi Adobe Photoshop CS6 lalu buat lembar kerja baru dengan resolusi sebesar 540x1080 pixels. Untuk membuat desain bagian dasar marker atau background penulis menggunakan beberapa desain yang sudah ada dan memiliki warna yang cukup tajam untuk dijadikan marker. Desain tersebut berekstensi .jpg. Hasilnya dapat dilihat pada gambar berikut.

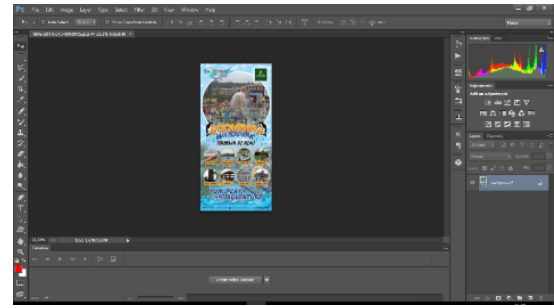

Gambar 4 Desain background marker

Implementasi Pembuatan AugmentedReality Pada Android

Tampilan Splash Screen

Halaman splash screen ini berfungsi untuk menampilkan identitas pembuat aplikasi. Splash screen pada aplikasi ini berbentuk gambar dengan tulisan Boombara Waterpark 
terbesar di riau. Tampilan splash screen ini di buat dalam scene yang diberi nama splash.

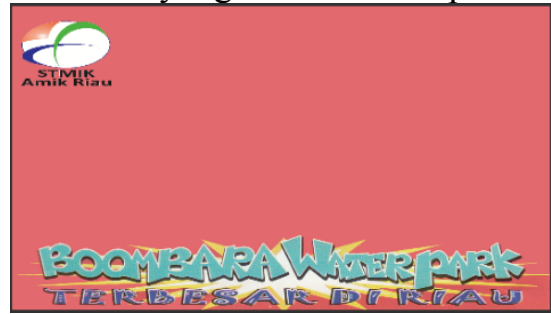

Gambar 5 Tampilan splash screen

\section{Tampilan Loading}

Halaman Loading ini berfungsi untuk memberikan jeda sebelum masuk ke scene selanjutnya. Berikut merupakan tampilan dari menu utama.

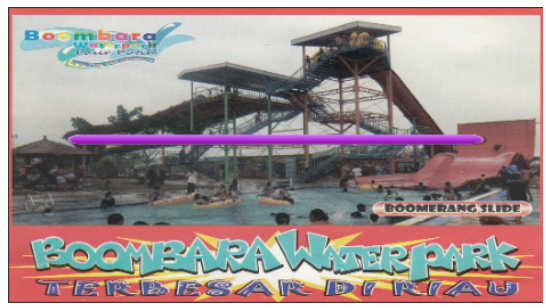

Gambar 6 Tampilan Loading

\section{Tampilan Menu Utama}

Pada scene menu utama terdapat empat menu pilihan yaitu menu ar camera, about as, download, dan exit. Berikut merupakan tampilan dari menu utama.

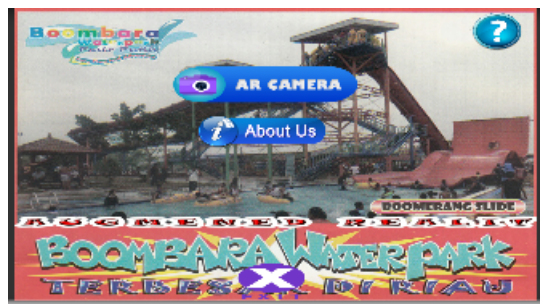

Gambar 7 Tampilan Menu Utama

\section{Hasil Pengujian Black Box}

Setelah dilakukan pengujian berdasarkan skenario pengujian yang telah dibuat maka hasil pengujian akan ditulis dalam bentuk tabel. Berikut adalah hasil pengujian berdasarkan skenario yang telah dibuat.

Tabel 1. Hasil Pengujian Skenario

\begin{tabular}{|c|c|c|c|c|}
\hline No. & Skenario & $\begin{array}{l}\text { Bagian } \\
\text { yang diuji }\end{array}$ & $\begin{array}{l}\text { Prosedur } \\
\text { Pengujian }\end{array}$ & $\begin{array}{l}\text { Hasil } \\
\text { Uji }\end{array}$ \\
\hline 1 & $\begin{array}{l}\text { Pengujian } \\
\text { menampilkan } \\
\text { splash screen }\end{array}$ & $\begin{array}{l}\text { Halaman } \\
\text { splash } \\
\text { screen }\end{array}$ & $\begin{array}{l}\text { Menekan } \\
\text { iconaplikasi } \\
\text { pada menu } \\
\text { utama }\end{array}$ & Berhasil \\
\hline 2 & $\begin{array}{l}\text { Pengujian } \\
\text { menampilkan } \\
\text { loading }\end{array}$ & $\begin{array}{l}\text { Halaman } \\
\text { loading }\end{array}$ & $\begin{array}{l}\text { Setelah } \\
\text { menampilkan } \\
\text { splash screen }\end{array}$ & Berhasiil \\
\hline 3 & $\begin{array}{l}\text { Pengujian } \\
\text { menampilkan } \\
\text { menu utama }\end{array}$ & $\begin{array}{l}\text { Halaman } \\
\text { menu } \\
\text { utama }\end{array}$ & $\begin{array}{l}\text { Setelah } \\
\text { menampilkan } \\
\text { loading }\end{array}$ & Berhasil \\
\hline 4 & Pengujian & Tombol & Menekan & Berhasil \\
\hline
\end{tabular}

tombol about

us pada menu utama

5 Pengujian tombol exit pada help about us

6 Pengujian tombol arcamerapada menu utama

7 Pengujian pendeteksian marker

Pengujian tombol reset pada halaman augmented reality

Pengujian tombol ratasi pada halaman Augmented Reality

10 Pengujian Tombol Zoom pada halaman Augmented Reality

Pengujian tombol home pada halaman augmented reality

12 Pengujian tombol kids pool pada halaman augmented reality

13 Pengujian tombol octopus slide pada halaman Augmented Reality

\section{Pengujian} tombol

boomerang slide pada halaman augmented reality

\section{Pengujian} tombol family slide pada halaman augmented reality

Pengujian tombol kolam ombak pada halaman augmented about us

pada menu

utama

Tombol

exit pada

help about

us

Tombol ar

camera

pada menu

utama

Halaman

augmented

reality

Tombol

reset pada

halaman

augmented

reality

Tombol

rotasi pada

halaman

augmented

reality

Tombol

zoom pada

halaman

augmented

reality

Tombol

home pada

halaman

augmented

reality

Tombol

kids pool

pada

halaman

augmented

reality

Tombol

octopus

slide pada

halaman

Augmented

Reality

Tombol

boomerang

slide pada

halaman

augmented

reality

Tombol

family

slide pada

halaman

augmented

reality

Tombol

kolam

ombak

pada

halaman tombol about

us pada menu

utama

Menekan

tombol exit

pada help

about us

Menekan

tombol ar

camera pada

menu utama

Mengarahkan Berhasil

kamera pada

marker

Menekan

tombol reset

pada

halaman

augmented

reality

Menekan

tombol rotasi

pada

halaman

augmented

reality

Menekan

Berhasil

tombol zoom

pada

halaman

augmented

reality

Menekan

tombol home

pada

halaman

augmented

reality

Menekan

tombol kids

pool pada

halaman

augmented

reality

Menekan

tombol

octopus slide

pada

halaman

Augmented

Reality

Menekan

tombol $a$

pada

halaman

augmented

reality

Menekan

tombol

family slide

pada

halaman

augmented

reality

Menekan

tombol

kolam ombak

pada

halaman

Berhasil

Berhasil

Berhasil

Berhasil

Berhasil

Berhasil

Berhasil

Berhasil

Berhasil

Berhasil 


\begin{tabular}{|c|c|c|c|c|}
\hline & reality & $\begin{array}{l}\text { augmented } \\
\text { reality }\end{array}$ & $\begin{array}{l}\text { augmented } \\
\text { reality }\end{array}$ & \\
\hline \multirow[t]{4}{*}{17} & $\begin{array}{l}\text { Pengujian } \\
\text { tombol water }\end{array}$ & $\begin{array}{l}\text { Tombol } \\
\text { water }\end{array}$ & $\begin{array}{l}\text { Menekan } \\
\text { tombol water }\end{array}$ & Berhasil \\
\hline & futsal pada & futsal pada & futsal pada & \\
\hline & halaman & halaman & halaman & \\
\hline & $\begin{array}{l}\text { augmented } \\
\text { reality }\end{array}$ & $\begin{array}{l}\text { augmented } \\
\text { reality }\end{array}$ & $\begin{array}{l}\text { augmented } \\
\text { reality }\end{array}$ & \\
\hline \multirow[t]{5}{*}{18} & Pengujian & Tombol & Menekan & Berhasil \\
\hline & tombol & exit pada & tombol & \\
\hline & exitpada menu & halaman & exitpada & \\
\hline & utama & тепи & halaman & \\
\hline & & utama & menu utama & \\
\hline
\end{tabular}

UJI JARAK MARKER

Tabel 2.Hasil pengujian skenario

\begin{tabular}{ccc}
\hline No. & Jarak Marker $(\mathbf{c m})$ & Hasil \\
\hline 1 & 100 & Tidak Terdeteksi \\
2 & 80 & Terdeteksi Lambat \\
3 & 60 & Terdeteksi Cepat \\
4 & 40 & Terdeteksi Cepat \\
5 & 20 & Terdeteksi Cepat \\
6 & 10 & Terdeteksi Lambat \\
7 & 5 & Tidak Terdeteksi \\
\hline
\end{tabular}

Uji jarak dilakukan dengan cara mengukur jarak kamera perangkat terhadap marker.

\section{Uji Sudut Kemiringan}

Uji sudut kemiringan dilakukan untuk mengukur seberapa jauh kemampuan sistem dalam mendeteksi marker apabila kamera atau marker dalam keadaan miring. Pengujian dilakukan dengan cara meletakkan marker pada bidang datar, kemudian kamera perangkat dimiringkan hingga maksimal 90o.

Tabel 3. Hasil Pengujian Sudut Kemiringan

\begin{tabular}{ccc}
\hline No. & Sudut Kemiringan $\left.\mathbf{(}^{0}\right)$ & Hasil \\
\hline 1 & 90 & Tidak Terdeteksi \\
2 & 75 & Terdeteksi Lambat \\
3 & 55 & Terdeteksi Cepat \\
4 & 35 & Terdeteksi Cepat \\
5 & 15 & Terdeteksi Cepat \\
6 & 0 & Terdeteksi Cepat
\end{tabular}

\section{Uji Tingkat Pencahayaan}

Uji tingkat pencahayaan dilakukan untuk mengetahui intensitas cahaya terhadap pengaruh kamera mendeteksi marker. Pengujian dlilakukan diruangan dengan menggunakan bola lampu.

Tabel 4.Hasil Pengujian Tingkat Pencahayaan

\begin{tabular}{ccc}
\hline No. & Intensitas Cahaya & Keterangan \\
\hline 1 & Terang & Terdeteksi Cepat \\
2 & Redup & Terdeteksi Lambat \\
3 & Gelap & Tidak Terdeteksi \\
\hline
\end{tabular}

\section{Analisis Hasil Pengujian}

Dari hasil pengujian yang telah dilakukan terhadap aplikasi, sistem beserta fungsi-fungsinya sudah berjalan dengan baik dan sesuai dengan rancangan aplikasi. Hasil pengujian dapat dijelaskan sebagai berikut:

1. Pengguna dapat menginstal aplikasi pada perangkat ponsel dan menggunakannya dengan baik.

2. Seluruh fungsi tombol yang disediakan dalam setiap scene dapat berjalan dengan baik sesuai dengan rancangan.

3. Marker dapat terdeteksi dengan baik pada jarak $20 \mathrm{~cm}$ sampai dengan $60 \mathrm{~cm}$ dari kamera perangkat yang digunakan

4. Marker dapat terdeteksi dengan baik pada kamera perangkat dengan sudut kemiringan 0o sampai dengan 55o.

5. Marker dapat terdeteksi dengan baik pada perangkat kamera dengan intensitas cahaya terang.

6. Seluruh animasi objek dapat berjalan baik sesuai dengan rancangan.

\section{KESIMPULAN}

Berdasarkan dari hasil peneltian dan pembahasan dalam skripsi ini, maka dapat di ambil kesimpulan sebagai berikut :

1. Aplikasi Dapat Berjalan pada android

2. Dengan adanya aplikasi ini, dapat membuat pengenalan wahana di Boombara waterpark akan lebih menarik, karena hanya dengan mengarahkan kamera smartphone ke marker pengunjung bisa melihat wahana Boombara Waterpark dalam bentuk 3D.

3. Intensitas cahaya sangat berpengaruh terhadap pendeteksian marker dalam memunculkan objek 3D.

\section{SARAN}

Berdasarkan kesimpulan diatas, penulis memberikan saran agar dapat dijadikan pertimbangan lebih lanjut dalam upaya pengembangan aplikasi ini yaitu :

1. Menampilkan objek dalam bentuk 3D tanpa Marker Atau Markeles Augmented Reality.

2. Aplikasi dapat di pergunakan untuk Ram di bawah 2GB.

3. Objek 3d agar lebih detail.

4. Menambahkan animasi pada objek Augmented Reality, seperti air dapat bergerak, ada burung beterbangan dan ada karakter manusia yang bergerak di setiap wahana di Boombara Waterpark. 


\section{UCAPAN TERIMA KASIH}

Pada kesempatan ini izinkan penulis mengucapkan terima kasih yang sedalam dalamnya kepada semua pihak yang telah memberikan dukungan, partisipasi, baik fasilitas dan kesempatan berdiskusi, khususnya kepada :

1. Politeknik Negeri Balikpapan.

2. Kampus STMIK Amik Riau

\section{DAFTAR PUSTAKA}

[1] M. O. Tambayong, A. S. Lumenta, B. A. Sugiarso, and J. T. Elektro-ft, "Implementasi Augmented Reality Pada Sistem Sirkulasi Darah Manusia," vol. 5, no. 3, pp. 49-57, 2016.

[2] J. Ilmiah, I. Komputa, and J. D. Bandung, "IMPLEMENTASI AUGMENTED REALITY ( AR ) PADA FOSIL PURBAKALA DI MUSEUM GEOLOGI

BANDUNG Teknik Informatika Universitas Komputer Indonesia Jurnal Ilmiah Komputer dan Informatika ( KOMPUTA )," 2014.

[3] T. W. Murtini and H. Werdiningsih, "KABUPATEN GUNUNG KIDUL KAWASAN WISATA TAMAN AIR ( WATER PARK ) PROVINSI DAERAH ISTIMEWA YOGYAKARTA," pp. 219 228.

[4] H. Chandra, Polygonal dan NURBS Modeling. Palembang: Maxikom, 2005. 